neighbourhood, the more tissue will be excited to reparative reaction, and the greater will be the proliferation and organization. Hence the fact that retinitis proliferans invariably springs from the disc or its vicinity. In the periphery there are two factors acting against such proliferation : first, the smallness of the hæmorrhage, which, however, may possibly be increased by repetition or multiplicity and confluence; second, and more important, the small amount of tissue which is capable of proliferating and inducing organization."

The proliferation of fibrous tissue in the scars of retino-choroidal ruptures would appear to be susceptible of a similar explanation. In these cases there is a considerable extravasation of blood from the choroid and retina into the vitreous, which is torn up, and, as it were, fractured by the rush of blood. In the ordinary vitreous hæmorrhage, due to rupture of retinal vessels, there is little mesoblastic tissue in contact with the blood capable of providing fibroblasts to bring about organization of the clot. The vitreous itself is inert, and its scanty cells appear to have little organizing capacity. Hence the blood is absorbed and only in exceptional cases does so-called "retinitis proliferans" occur. When both choroid and retina are ruptured the mesoblastic choroid affords an ample supply of active fibroblasts, and the clot organizes into a mass of fibrous tissue in exactly the same manner as in a hæmorrhage into the other connective tissues.

If this suggestion is correct, it provides an argument against the method of removing foreign bodies from the vitreous by introducing the pole of the small magnet through an incision which perforates sclerotic, choroid and retina. By this method the choroidal fibroblasts are enabled to escape into the track of the wound and lead to exuberant fibrous tissue formation. By the alternative method of drawing the foreign body into the anterior chamber with the giant magnet, preparatory to its removal from the eye, the track is not put into relationship with any considerable mass of potential fibroblasts, and consequently little fibrous tissue is likely to be formed. The risks of detachment of the retina, etc., from contraction of bands of scar tissue are thus minimized.

\title{
ANNOTATIONS
}

\section{Specialism and Special Hospitals}

IT is scarcely necessary in a journal devoted to a special branch of medicine to enumerate the arguments in favour of specialism in medicine. Yet conservative instincts are strong, and there are still 
many members of our profession who view with ill-concealed disapproval the application of the principle of the division of labour to the science and art of medicine. And indeed their attitude is but the expression of an awareness of the disadvantages and dangers of specialism which its exponents are liable to forget; and as such it should be borne patiently and treated with consideration. For each new step in progress entails new relationships which, improperly dealt with, lead to disaster. The man who makes the eye of a needle is a useless member of society unless he acts in fitly ordered collaboration with those who attend to the innumerable other details of the manufacture of needles. Division of labour, whenever and wherever it occurs, inexorably demands appropriately adapted co-ordination. So far as ophthalmology is concerned, its success leads us to-conclude that co-ordination is at any rate adequate, even if it be not ideal.

Specialism is the inevitable outcome of the increased knowledge and greater complexity of modern life. It is a normal product of the evolutionary process, and this fact is the crucial argument in its favour. When Saunders founded the first great Eye Hospital in London he did it to fill what is commonly described as a felt need. Others had felt the need as well as he, and Guthrie ran him close in the race to fill it. Probably neither had any idea that he was sowing the seeds of a new specialism, but the seeds were there. They fell into good ground arid flourished exceedingly. The new hospitals fulfilled their primary object. The patients were treated, and they were treated better than they would have been under pre-existing circumstances. Not only so, but the surgeons gained more experience of eye diseases and how to treat them, so that they became better craftsmen. Being better craftsmen they devised better tools. In course of time some of the tools became so elaborate and expensive, such as the giant magnet, that to-day they cost large sums of money. Few general hospitals provide these expensive instruments for sporadic cases of intraocular foreign bodies, so that the development of special hospitals leads to economy amongst its other benefits. We need not enumerate any others. Special hospitals have fully justified their existence in civil life.

To-day we are in the midst of a great war and all our energies are focussed on that immense theme. As ophthalmic surgeons we are specially interested in the vast multitude of wounded soldiers who have sustained injuries to their eyes. We may well be proud of the great organization which Sir Alfred Keogh has built up, and which, with a success never before obtained in any war, grapples with the innumerable medical and surgical problems of the Army. The success is founded upon experience derived from civilian practice, modified to suit the special requirements. That experience may 
perchance yet hold lessons which have not hitherto received full recognition.

\section{The visual requirements of military aviators}

The great and growing importance of aviation from the military standpoint and the exacting nature of the work required obviously necessitate a standard of physical fitness different from that required for the ordinary soldier. The visual standard will also have to be superior. C. P. Small, of Chicago, in a recent paper (Jl. Amer. Med. Assoc., March 17, 1917), has raised the question and gives the standard that should be required as follows:-

" 1 . Uncorrected vision of $20 / 20$ in each eye. 2. Binocular vision. 3. Absence of nystagmus. 4. Normal muscle balance and competent ocular muscles. 5. Normal pupillary reaction and no pupillary irregularities when dilated. 6. Normal media and fundi. 7. Normal visual fields, by perimetric examination. 8. Normal colour sense."

In the body of the paper he asserts that every case must be examined with a mydriatic and comes essentially to the conclusion that nothing less than absolute perfection will do. E. Blaauw, of Buffalo, wrote a letter to the same journal, April 21, 1917, in which hc expressed doubts as to the necessity for good colour vision, binocular vision, and mydriatic examination. The correspondence was also carried on in the Ophthalmic Record, June, 1917, Blaauw, in that journal, pointing out the necessity of not being dogmatic from an ophthalmic point of view and of being guided by actual experience.

The problem in America is probably not quite the same as with us. The available material is greater, and no one will deny that the nearer perfection one can get the better. So, if Small's contention that nothing less than perfection will serve is correct, our part is rendered very simple, and the matter is at an end. But, before settling this point, it is worth considering what practical aviators have to say on the matter. We have notes of three cases of aviators, two of whom have been decorated for excellent work on the West front, with considerable amounts of mixed astigmatism. None of them wears his correction while flying, although that correction gives him normal vision in each eye, whereas when uncorrected the vision of the better eye is in one $6 / 9$, and in the other two 6/12, the vision of the worse eye being $6 / 18,6 / 36$, and $6 / 12$ respectively. In the one who has an eye with only $6 / 36$ there is imperfect binocular vision with a slight divergence.

It is obvious that successful flying can quite well be done with distant vision slightly below the normal. On the other hand, the necessity for quick and accurate reading of the dials of the various 